\title{
Correction to: Sustainability of European Food Quality Schemes
}

\author{
Filippo Arfini and Valentin Bellassen
}

\section{Correction to: \\ F. Arfini, V. Bellassen (eds.), Sustainability of European Food Quality Schemes, https://doi.org/10.1007/978-3-030-27508-2}

In the original version of this book, Chapter 5 and Chapter 14 was inadvertently published with errors in chapter title which is corrected as "PGI Hom Mali Thung Kula Rong-Hai Rice in Thailand" and "PGI Buon Ma Thuot Coffee in Vietnam," in this revised version of the book.

The updated online version of these chapters can be found at https://doi.org/10.1007/978-3-030-27508-2_5

https://doi.org/10.1007/978-3-030-27508-2_14 